\title{
Gene Therapy: A Strategy for the Treatment of Alzheimer's Disease
}

\section{Danielle Weber-Adrian}

\author{
University of Toronto
}

In 2010, an estimated 35.6 million people worldwide were suffering from dementia ${ }^{1}$. This number is expected to increase, resulting in a global disease burden of $115^{4}$. million people by $2050^{1}$. Alzheimer's disease (AD) is the most common form of dementia, and is characterized by memory loss ${ }^{2}$, gross atrophy of the brain, and the accumulation of both intraneuronal tau protein aggregates and extracellular amyloid- $\beta$ protein ${ }^{3}$. Gene therapy allows for therapeutic treatment through the continuous expression of a transgene, and is currently under clinical investigation for a variety of neurological diseases including $A D^{4}$. Gene therapy has two main delivery conduits: viral vectors and nonviral vectors ${ }^{5}$. However, a challenge in $A D$ treatment with gene therapy is the delivery of the therapeutic vector into the brain. Systemic delivery from the blood is hindered by the presence of the blood brain barrier (BBB), which prevents passive diffusion of $~ 98 \%$ of small molecule drugs and limits the passage of gene therapy vectors ${ }^{6}$. This short review will cover current delivery strategies for overcoming the BBB along with a sample of genes that have been investigated as $A D$ therapeutics.

Invasive delivery requires surgical administration of a therapeutic into the brain through trans-cranial injection, either into the parenchyma or intracerebroventricular space $^{6}$. Intracerebroventricular injection allows for delivery to the entire central nervous system through circulation in the cerebrospinal fluid (CSF); however, this limits delivery in areas of the brain with less CSF exposure, and cannot target delivery to specific brain regions. Additionally, the rate of efflux from the brain into the CSF is much higher than the diffusion rate from the CSF into the brain ${ }^{6}$. Parenchymal injections mediate targeted delivery to specific brain regions, but this technique is associated with risks of surgical complications ${ }^{6}$.

Despite these limitations, direct injection provides the only AD-related gene therapy clinical experience to date. As most cases of $A D$ are attributed to idiopathic causes, as opposed to genetic predisposition, gene-mediated therapeutic strategies typically focus on neuroprotection and repair. ${ }^{7}$ Thus far, there have been two clinical trials investigating gene therapy for the treatment of $A D^{8}$. Both trials have investigated delivery of neurotrophic growth factor (NGF), which has been shown to prevent cholinergic neuron degeneration ${ }^{8}$. This is of relevance to AD since memory impairment has been directly correlated with degeneration of cholinergic neurons ${ }^{9}$. The phase I results of a clinical trial using intracranial delivery of NGF-expressing fibroblasts showed a reduction in the rate of cognitive decline ${ }^{8}$. A phase II trial using a viral vector to deliver NGF to the basal forebrain is currently underway ${ }^{8}$. Other gene-mediated targets for the treatment of $A D$ in preclinical models have included brain-derived neurotrophic factor (BDNF), fibroblast growth factor 2 (FGF2), and anti-inflammatory cytokine interleukin-4 (IL-4) ${ }^{7,8}$. BDNF gene therapy has been shown to restore spatial memory performance in $A D$ model rodents, partially rescue age-associated changes in gene expression, and prevent neuronal cell death when delivered prior to surgically-induced brain lesions ${ }^{8}$. FGF2 gene therapy directed to the hippocampus has also shown improvement in spatial learning, enhanced clearance of amyloid- $\beta$ fibrils, and increased neurogenesis in an AD mouse model ${ }^{8}$. Lastly, IL-4 gene delivery to the hippocampus improved spatial learning and increased neurogenesis, while decreasing hypertrophy, nonspecific activation of glial cells, and amyloid $\beta$ deposition ${ }^{8}$. Although these therapeutics show potential for the treatment of $A D$, the safety of gene delivery to the brain could be enhanced by a non-surgical distribution method.

Non-invasive techniques for delivery to the brain, which do not require transporter-mediated delivery across the $B B B$, include intranasal delivery, chemical disruption of the $\mathrm{BBB}$, and localized permeabilization of the BBB with 
focused ultrasound ${ }^{6,10}$. Intranasal delivery bypasses the BBB by delivering the drug through the submucus space of the nose directly into the CSF. However, this technique is restricted in volume $(\leq 100 \mu \mathrm{L})$ and associated with the same limitations as intracerebroventricular delivery ${ }^{6}$. Chemical mediated BBB disruption causes global permeabilization of the BBB, but is largely associated with leakage of toxic plasma proteins into the central nervous system ${ }^{6}$. Lastly, MRI-guided focused ultrasound treatment allows for transient and localized BBB permeabilization, and has been shown to mediate targeted gene delivery to the brain in a mouse mode ${ }^{10}$. While promising, this technique has yet to be used in a clinical context. Additionally, non-invasive methods for gene delivery to the brain face the challenge of curtailing gene expression in non-target organs after systemic delivery, which could result in side effects.

In conclusion, preclinical and clinical investigations in gene therapy for AD show promise, and suggest that gene therapy could surpass the limitations of traditional pharmacology by providing treatment in a sustained manner. Future studies will hopefully lead to success in clinical trials, as well as progress in developing safer methods for therapeutic delivery.

\section{References}

1. Prince M, Bryce R, Albanese E, Wimo A, Ribeiro W, Ferri CP. The global prevalence of dementia: a systematic review and metaanalysis. Alzheimers Dement [Internet]. Elsevier Ltd; 2013 Jan [cited 2014 Jul 10];9(1):63-75.e2. Available from: http://www.ncbi.nlm.nih.gov/pubmed/23305823

2. Ye $X$, Tai W, Zhang $D$. The early events of Alzheimer's disease pathology: from mitochondrial dysfunction to BDNF axonal transport deficits. Neurobiol Aging [Internet]. 2012 Jun [cited 2014 Dec 22];33(6):1122.e1-10. Available from: http://www.ncbi.nlm.nih.gov/pubmed/22212405

3. Allen SJ, Watson JJ, Dawbarn D. The Neurotrophins and Their Role in Alzheimer's Disease. Curr Neuropharmacol. 2011;9:559-73.

4. Ginn SL, Alexander IE, Edelstein M I, Abedi MR, Wixon J. Gene therapy clinical trials worldwide to 2012 - an update. J Gene Med. 2013;15:65-77.

5. Lentz TB, Gray SJ, Samulski RJ. Viral vectors for gene delivery to the central nervous system. Neurobiol Dis [Internet]. Elsevier Inc.; 2011 Oct 7 [cited 2012 Aug 1];48(2):179-88. Available from: http://www.ncbi.nlm.nih.gov/ pubmed/22001604

6. Pardridge WM. Blood-brain barrier delivery. Drug Discov Today [Internet]. 2007 Jan [cited 2014 Mar 25];12(1-2):54-61. Available from: http://www. ncbi.nlm.nih.gov/pubmed/17198973

7. Simonato M, Bennett J, Boulis NM, Castro MG, Fink DJ, Goins WF, et al. Progress in gene therapy for neurological disorders. Nat Rev Neurol [Internet]. Nature Publishing Group; 2013;9(5):277-91. Available from: http://www.pubmedcentral.nih.gov/articlerender.fcgi?artid=3908892\&too l=pmcentrez\&rendertype=abstract

8. Woodbury M, Kiyota T, Ikezu T. Gene Delivery and Gene Therapy for Alzheimer's Disease. In: Bo X, Verhaagen J, editors. Gene Delivery and Therapy for Neurological Disorders [Internet]. New York, NY: Springer Science+Business Media; 2015. p. 85-119. Available from: http://link. springer.com/10.1007/978-1-4939-2306-9

9. Tuszynski MH. Nerve growth factor gene therapy in Alzheimer disease. Alzheimer Dis Assoc Disord [Internet]. 2007;21(2):179-89. Available from: http://www.ncbi.nlm.nih.gov/pubmed/17545746

10. Thévenot $E$, Jordão JF, O'Reilly MA, Markham K, Ying-Qi L, Foust $K$, et al. Targeted delivery of scAAV9 to the brain using MRI-guided focused ultrasound. Hum Gene Ther [Internet]. 2012 Jul 27 [cited 2012 Sep 7];23:113. Available from: http://www.ncbi.nlm.nih.gov/pubmed/22838844

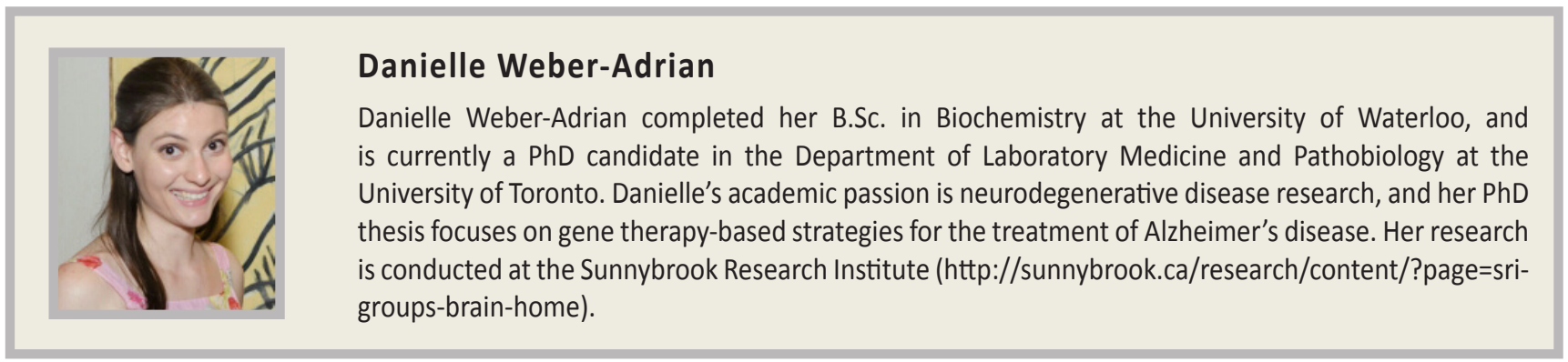

